\title{
Pediatric Brain Tumors: Current Treatment Strategies and Future Therapeutic Approaches
}

\author{
Sabine Mueller* and Susan Chang ${ }^{\dagger}$ \\ *Department of Neurology, Division of Child Neurology, University of San Francisco, San Francisco, California 94117; \\ ${ }^{\dagger}$ Department of Neurosurgery, Division of Neuro-Oncology, University of San Francisco, San Francisco, California 94117
}

Summary: Pediatric CNS tumors are the most common solid tumors of childhood and the second most common cancer after hematological malignancies accounting for approximate 20 to $25 \%$ of all primary pediatric tumors. With over 3,000 new cases per year in the United States, childhood CNS tumors are the leading cause of death related to cancer in this population. The prognosis for these patients has improved over the last few decades, but current therapies continue to carry a high risk of significant side effects, especially for the very young. Currently a combination of surgery, radiation, and chemotherapy is often used in children greater than 3 years of age. This article will outline current and future therapeutic strategies for the most common pediatric CNS tumors, including primitive neuroectodermal tumors such as medulloblastoma, as well as astrocytomas and ependymomas. Key Words: Pediatric brain tumor, therapy, primitive neuroectodermal tumors, medulloblastoma, astrocytoma, ependymoma.

\section{PRIMITIVE NEUROECTODERMAL TUMORS}

Primitive neuroectodermal tumors (PNETs) consist of poorly undifferentiated, small, monomorphic round cells. Based on their location, these tumors are divided into infratentorial and supratentorial primitive neuroectodermal tumors (sPNET). The term medulloblastoma is generally used for PNETs located infratentorially in the posterior fossa. Growing evidence suggests that these tumors are a heterogenous group of undifferentiated tumors, which might have an impact on specific treatment options. Specifically, different molecular genetic aberrations in the tumor cells of medulloblastomas and sPNETs were identified, suggesting that different signaling pathways are involved in the tumorigenesis of these tumors. $^{1-4}$

\section{Medulloblastoma}

Introduction. Medulloblastomas account for 20\% of all childhood CNS tumors and $40 \%$ of all cerebellar tumors. Peak occurrence is at 4 years of age. Approximately 10 to $15 \%$ are diagnosed in infancy and require specific treatment considerations, which will be dis-

Address correspondence and reprint requests to: Sabine Mueller, $\mathrm{MD}, \mathrm{PhD}$, University of San Francisco, California, 350 Parnassus Avenue, Suite 609, San Francisco, CA 94117. E-mail: muellers@ neuropeds.ucsf.edu. cussed in detail in this article. Treatment protocols are based on risk stratification, which takes into account age at presentation, residual disease, as well as evidence of disseminated disease. Patients greater than 3 years of age with minimal residual disease are classified as an average risk group. Children younger than 3 years, with subtotal resection and/or evidence of disseminated disease are grouped into high-risk patients.

\section{Current treatment strategies}

Surgery. Surgical resection remains the mainstay of therapy with the goal of gross total resection (GTR). Virtually all patients who present with a posterior fossa mass will undergo an open craniotomy. Studies have shown that patients with less then $1.5 \mathrm{~cm}^{2}$ residual disease had improved survival. ${ }^{5-7}$ Some patients might require a ventricular shunt or third ventriculostomy prior to resection of the tumor. The majority of patients will have resolution of the hydrocephalus after tumor resection, but approximately $40 \%$ will require permanent shunt placement. Prognostic factors for permanent shunting are young age, significant pre-surgical hydrocephalus, and large tumors. ${ }^{8}$ One postsurgical complication characteristically developing after posterior fossa tumor resection is the cerebellar mutism syndrome (CMS) also referred to as the posterior fossa syndrome. This entity typically starts within 1 to 2 days after surgery, persists for weeks 
to months, and consists of paucity of speech leading to mutism, hypotonia, ataxia, and emotional instability. In addition, brainstem dysfunction can be seen, including dysphagia, facial weakness, and abducens paralysis. In one large study of 450 children, CMS developed after surgery in 107 (24\%). Only brainstem involvement was predictive for the development of CMS. ${ }^{9}$ Another series analyzed 253 children in which CMS developed in 20. All of these cases had brainstem involvement. ${ }^{10}$ Evidence of hydrocephalus also appears to exacerbate the development of CMS. ${ }^{11}$ Individual case studies report on successful use of dopamine agonists, such as bromocriptine for the treatment of CMS, ${ }^{12,13}$ but unfortunately children are often left with dysarthric speech. Therefore, careful resection is warranted, especially in children with brainstem involvement.

\section{Radiation}

Medulloblastomas are very radiosensitive tumors and adjuvant therapy with radiation has been the standard of care in children $>3$ years of age. The reported, longterm side effects of radiation therapy, such as hearing loss, ${ }^{14,15}$ cognitive decline, ${ }^{16}$ endocrine abnormalities, ${ }^{17}$ vascular complications, ${ }^{18}$ as well as secondary malignancies, ${ }^{19}$ have inspired many investigators over the years to try to reduce the amount of radiation, as well as the radiation field albeit with limited success. The Pediatric Oncology Group (POG) and Children's Cancer Group (CCG), now collectively known as the Children's Oncology Group (COG), compared in a prospective trial (POG 631/COG 923) reduced neuroaxis radiation of 23.6 Gy to the standard regimen of 36 Gy with equal posterior fossa radiation (54 Gy) for children with average risk medulloblastoma. The interim analysis indicated an increased risk of early relapse with reduced radiation. ${ }^{20}$ The long-term follow-up analysis of these children confirmed these early results, but also showed that over time these differences are less pronounced. The 8-year analysis of this trial revealed no statistical difference between the two treatment groups. ${ }^{21}$ Since then, many studies have focused on the introduction of chemotherapy to reduce radiation exposure, but maintain adequate survival, which will be discussed below. The introduction of conformal radiation enabled radiation oncologists to reduce the radiation field. A multi-institutional prospective trial using 23.4 Gy craniospinal irradiation followed by conformal posterior fossa (36 Gy) and primary site irradiation (55.8 Gy), and dose-intensive chemotherapy for average risk medulloblastoma achieved similar disease control than irradiation of the complete posterior fossa. ${ }^{22}$ Other investigators used a boost dose to the tumor bed, instead of irradiating the entire posterior fossa using conformal radiation therapy with 5-year overall survival (OS) rates of $84 \% .{ }^{23}$ Proton beam therapy is another alternative to conventional radiation therapy. The benefit of using proton beams is the higher proportion of tumor versus normal tissue distribution. An ongoing phase II trial at the Massachusetts General Hospital in Boston is assessing the efficacy and long-term cognitive outcome in patients who receive proton beam therapy to the posterior fossa and craniospinal axis. Radiosurgery can successfully be used for local tumor control in patients with recurrent or residual disease. ${ }^{24-26}$ However, stereotactic radiation as primary treatment modality is limited given the propensity of medulloblastomas for dissemination and treatment failure can occur due to subclinical craniospinal metastasis.

The current standard for average risk medulloblastoma in North America includes postoperative craniospinal irradiation of $23.4 \mathrm{~Gy}$, plus a boost to the posterior fossa of 54 Gy followed by 12 months of chemotherapy. This regimen has resulted in a 5 -year OS of $80 \%$ or better. ${ }^{27}$ In high-risk disease, 36 Gy craniospinal irradiation, plus a boost at the posterior fossa of $54 \mathrm{~Gy}$, followed by chemotherapy is standard. Ongoing trials are investigating the benefit of chemotherapy during irradiation.

\section{Chemotherapy}

Lowering the radiation dose without adding chemotherapy has led to worse outcomes in children with medulloblastoma. Many studies have investigated the role of chemotherapy in addition to radiation therapy with the goal to reduce the amount of radiation exposure. A range of different chemotherapeutic agents has been used and is now standard of care in the management of children with medulloblastoma in all risk groups. Alkylators and platinum compounds, such as lomustine, cyclophosphamide, and cisplatin remain key therapeutic agents. Vincristine is often administered weekly during irradiation and as adjuvant chemotherapy. Children with average risk disease, who were treated with craniospinal irradiation of 23.4 Gy and 55.8 Gy to the posterior fossa, as well as adjuvant chemotherapy (lomustine, vincristine, and cisplatin) showed a progression-free survival (PFS) of $86 \%( \pm 4 \%)$ at 3 years and $79 \%( \pm 7 \%)$ at 5 years. ${ }^{28}$ The European Hirntumor (HIT) 91 trial compared outcome in patients with average risk medulloblastoma receiving either neoadjuvant chemotherapy (prior to radiation therapy) or postradiation chemotherapy. In this study, patients with residual tumor and M1 disease were included, which differs from most United States' studies. The 5-year PFS in the postradiation chemotherapy arm was reported at $78 \%$ ( \pm $6 \%$ ), and in the neoadjuvant chemotherapy arm as $65 \%$ ( \pm $5 \%) .{ }^{29}$ The PNET III trial conducted in the United Kingdom by the International Society of Pediatric Oncology compared PFS in average risk medulloblastoma patients (including patients with M1 disease) treated with either radiation therapy alone (35 Gy of craniospinal irradiation with a total dose of 55 Gy to the posterior fossa) or a combination of chemotherapy (vincristine, carboplatin, cy- 
clophosphamide, and etoposide) and radiation therapy. The 5 -year PFS was 74\% in the group receiving chemotherapy and radiation therapy compared with $60 \%$ for the radiation group. ${ }^{30}$ Collectively, these studies confirm the benefit of adjuvant chemotherapy for the treatment of average risk medulloblastoma. Currently, the regimen reported by Packer et al., ${ }^{28}$ as previously described remains the standard of therapy for low-risk medulloblastoma patients in North America.

For high-risk medulloblastoma patients, the priority remains to improve survival. Average event-free survival (EFS) at 5 years for high-risk medulloblastoma ranges from 34 to $40 \%$ across studies. ${ }^{31}$ Multiple studies have used different chemotherapy protocols, including neoadjuvant chemotherapy in combination with surgery and radiation to improve survival with moderate success. ${ }^{7,29}$ The use of prolonged neoadjuvant chemotherapy resulted in inferior outcomes compared with those obtained with shorter times between surgery and radiation therapy. ${ }^{29,31}$ Other avenues like myeloablative chemotherapy with stem cell rescue, as well as intrathecal and intravenous methotrexate have been used for the treatment of high-risk medulloblastomas with various success. $^{32,33}$ The best outcome for high-risk medulloblastoma patients to date was achieved by craniospinal irradiation (36 Gy M0-1; 39.6 Gy M2-3) with a boost to the primary tumor site after maximal surgical resection followed by dose-intensive cyclophosphamide, vincristine, and cisplatin chemotherapy with autologous peripheral blood stem cell rescue. The 5-year EFS was 70\%. ${ }^{34}$ The COG (COG 99701) treated 57 patients with metastatic medulloblastoma with vincristine and carboplatin while receiving radiation therapy (36 Gy for craniospinal irradiation), followed by monthly treatment with cyclophosphamide and vincristine. The-4 year OS and EFS were reported at $81 \%( \pm 5 \%)$ and $66 \%( \pm 6 \%)$, respectively. Patients with anaplasia had worse outcomes (4year OS $65 \% \pm 11 \%$ ) compared with patients with no anaplasia (4-year OS $89 \% \pm 5 \%){ }^{35}$ This indicates that chemotherapy is also pivotal for the treatment of highrisk medulloblastoma patients, but ongoing studies are investigating the best regimen for these patients.

\section{Medulloblastoma in the very young child}

Medulloblastoma is the most common brain tumor in childhood and one third of the cases are present in the first years of life. Management of these very young patients remains challenging since the immature brain is particularly susceptible to the toxicity of current treatment options. There is belief that medulloblastomas in the very young child have a more aggressive behavior and a higher incidence of metastasis at the time of diagnosis, although the data is limited. Evans et al ${ }^{36}$ reported that $34 \%$ of children under the age of 4 years presented with disseminated disease compared with only $14 \%$ of children aged 4 years or older. Similar results were reported separately with $62 \%$ of children less than 5 years of age demonstrating metastatic disease versus $38 \%$ in children older than 5 years of age. ${ }^{37}$ The impact of age on prognosis is difficult to assess because younger patients normally receive different treatment modalities than older children. In an attempt to delay or obviate radiation therapy, multiple studies have been performed using different chemotherapy regimens.

In 1985 van Eys et al. ${ }^{38}$ published their encouraging results using postoperative neoadjuvant chemotherapy. Two of 6 children younger than 4 years of age with medulloblastoma treated with a postoperative course of mechlorethamine, vincristine, procarbazine, and prednisone remained in complete remission. In the mid1980s, the POG conducted a trial (referred to as BabyPOG I) enrolling 102 children less than 3 years of age with brain tumors in which prolonged postoperative chemotherapy was given with an attempt to delay radiation therapy. The 5-year PFS of 62 children with medulloblastoma less than 3 years of age was reported at $31.8 \%$ $( \pm 8.3 \%)$ and the 5-year OS at $39.7 \%( \pm 6.9 \%)$ using a combination of cyclophosphamide, vincristine, cis-platinum, and etoposide. Radiation was delayed until 3 years of age. The main predictor for survival was extent of surgical resection. Tweny children undergoing GTR had a 5-year OS of $60 \%$ compared with 33 children who had subtotal resection and who had a 5-year OS of $32 \% .^{39}$ Other studies investigated a similar approach. The CCG used the "8-in-one-day" regimen followed by either radiation after two cycles of chemotherapy versus craniospinal irradiation 1 year after diagnosis and completion of maintenance chemotherapy. Forty-six children with medulloblastoma were less than 18 months old. The 3 -year PFS was $22 \%( \pm 6 \%)$. Thirty percent were alive and disease-free at a mean follow-up of 72 months. ${ }^{40}$ The poorer outcome in the " 8 -in-one-day" regimen is probably best explained by the less intensive chemotherapy regimen in this study compared to the Baby-POG I trial. One of the largest trials for young children from the CCG (CCG 9921) reported on 92 children younger than 3 years of age, of which 61 patients had no evidence of metastasis by time of diagnosis. Children were treated with two different induction schemes followed by $8 \mathrm{cy}-$ cles of maintenance chemotherapy. Children with no residual tumor after induction therapy and no metastasis at diagnosis did not receive radiation therapy unless they had evidence of recurrence. The EFS in the nonmetastatic group was $41 \%$ in 38 patients with GTR and $26 \%$ in 23 patients with residual tumor. In 31 patients with metastatic disease the EFS was $25 \% .^{41}$ The Head-Start I study was designed to avoid radiotherapy. After GTR and induction chemotherapy with cisplatin, vincristine, etoposide, and cyclophosphamide, the patients underwent myeloablative consolidation chemotherapy with 
carboplatin, thiotepa, and etoposide, and autologous stem cell rescue (ASCR). Two-year EFS and OS was 38\% and $62 \%$, respectively. ${ }^{42}$ The induction chemotherapy was intensified during the Head Start II protocol by addition of methotrexate, which showed promising results. In this study, 9 children less than 3 years of age with disseminated medulloblastoma showed treatment response $(8$ with complete response and 1 child with partial response). ${ }^{43}$ The Head Start III protocol is currently investigating the role of oral etoposide and temozolamide (TMZ). Current studies include standardized neuropsychological evaluations in comparison to questionnaires and parent interviews, which will be important in evaluating quality of life and long-term treatment side effects.

In summary, the optimal treatment for patients less than 3 years of age presenting with medulloblastoma has yet to be established. Promising results with intensified induction chemotherapy followed by high-dose chemotherapy with ASCR might justify further evaluation of these regimens, despite significant toxicity. Given the relatively low frequency of very young children with medulloblastoma, only international collaborations will lead to robust assessments of efficacy, quality of life, and neurocognitive outcomes of different treatment strategies.

\section{Supratentorial primitive neuroectodermal tumors}

Introduction. sPNETs consist of a heterogeneous group of highly malignant tumors arising at various locations within in the CNS but exhibit similar histology. sPNET account for only 1 to $2.5 \%$ of all childhood tumors. ${ }^{44,45}$ The mean age of onset is around 3 years of age and these tumors carry a very poor prognosis with a 5 -year OS of usually less than $30 \%$. Ongoing controversy exists if these tumors should be classified based on their location, pattern of differentiation, or if they should be seen as a single entity, which can arise throughout the CNS. As previously outlined, molecular studies revealed significant differences between SPNET and medullolastoma supporting the fact that at least infra- and supratentorially located PNETs are different entities. Commonly accepted poor prognostic factors are young age at presentation and evidence of dissemination. Metastasis outside the CNS is exceedingly rare and occurs in less than $0.5 \%$ of patients. ${ }^{46}$ The Chang classification system is commonly used for staging. ${ }^{47}$ Overall sPNETs have a worse outcome and respond less to current therapy regimens compared to medulloblastomas.

\section{Surgery}

Surgical resection remains the mainstay of initial therapy in patients presenting with sPNET. To what extent GTR or near GTR has a positive influence on survival remains controversial. ${ }^{48-52}$ The CCG-921 trial showed a better trend regarding outcome for patients with residual disease less than $1.5 \mathrm{~cm}^{2}$, which did not achieve statistical significance possibly due to the small number of centrally reviewed patients. ${ }^{48} \mathrm{~A}$ review of 22 patients with SPNET reported a 5-year PFS of 53\% for patients who underwent GTR compared with $25 \%$ of those who only underwent partial resection or biopsy. ${ }^{52}$ An analysis of patients treated in Italy with chemotherapy and hyperfractionated accelerated radiation therapy demonstrated that patients with GTR had a PFS of $83 \%$ ( \pm $15 \%)$ versus $32 \%( \pm 18 \%)$ in patients with residual disease after surgery. However, due to the small sample size, this did not reach statistical significance. ${ }^{53}$ In the HIT 88/89 and 91 trials patients with incomplete resection fared as well as those with GTR. ${ }^{54}$ This is in concordance with a retrospective analysis from Canada that reported OS was not affected by the initial degree of surgical resection. ${ }^{46}$

In summary, surgical resection remains the standard of care for patients with SPNET, but to what degree the extent of resection matters remains controversial. The available information is limited to date, and further trials are needed to readdress the role of aggressive surgery given the associated morbidity.

\section{Radiation therapy}

Radiation therapy plays an important role in the treatment regimen for children with sPNET. Given the low incidence rate of these tumors, most of our current knowledge derives from subset analysis of larger trials or retrospective single institution experiences. Dosing, timing, and target volume of radiation continues to be subject of debate, but few conclusions can be drawn based on existing data. As previously outlined, the young patients (less than 3 years of age) are especially at high risk to develop adverse reactions to radiation therapy. The relative high percentage of young children presenting with SPNET makes the evaluation of treatment failure versus inherited differences in the tumor biology difficult, given that these patients often receive limited amounts of radiation. In 1990, the French Society of Pediatric Oncology (SFOP) pilot study was initiated as a trial to treat children less than 5 years of age with brain tumors (excluding gliomas) with postoperative conventional chemotherapy to delay radiation therapy. Twentythree children were diagnosed by central review with sPNET, along with two additional parallel review cases that were included in the analysis. The OS was documented at 1,2, and 5 years with $48 \%, 29 \%$, and $14 \%$, respectively. The authors concluded that postoperative chemotherapy without radiation is not adequate for the treatment of children with sPNET. ${ }^{55}$ The German trials HIT 88/89, and HIT 91, revealed important information regarding the benefit of radiotherapy. A total of $63 \mathrm{pa}-$ tients with sPNET were treated with adjuvant chemotherapy in these studies. The 3-year PFS for children 
treated with radiotherapy, according to guidelines was $49.3 \%$, whereas children with major treatment violations regarding radiation therapy achieved a 3 -year PFS of only $6.7 \% .{ }^{54} \mathrm{~A}$ recent retrospective analysis from Canada investigated outcome in 48 patients treated between 1995 and 2005 for sPNET. The 4-year survival was 37.7 $\%( \pm 7.6 \%)$ with a median follow-up of 42 months. The only independent significant factor associated with improved outcome was the use of radiation therapy. ${ }^{46} \mathrm{~A}$ recent analysis from the University of California, San Francisco revealed that patients who received upfront radiation therapy have longer OS, as well as PFS. ${ }^{56}$

In summary, treatment for children greater than 3 years of age with sPNET consists of surgical resection followed by radiation therapy. Currently, the dose for craniospinal irradiation ranges from $23.4 \mathrm{~Gy}$ to $36 \mathrm{~Gy}$, and the suggested tumor dose is between 54 Gy and $56 \mathrm{~Gy}$.

\section{Chemotherapy}

The devastating side effects of radiation therapy led to multiple studies investigating different chemotherapy regimens to improve outcome. One landmark study by the COG demonstrated that patients older than 18 month (17 patients) with sPNET in the pineal region treated with chemotherapy ("8-drugs-in-1-day" or a combination of vincristine, lomustine, and prednisone) and craniospinal irradiation had a PFS at 3 years of $61 \%$ ( \pm $13 \%)$, which was superior than prior published results. All infants in this study ( 8 patients) that were only treated with chemotherapy ("8-drugs-in-1-day") had progressive disease at a median of 4 months. ${ }^{57}$ In the HIT $88 / 89$, and HIT 91, studies the treatment with pre-irradiation chemotherapy (ifosfamide, etoposide, methotrexate, cisplatin, and cytarabine) or chemotherapy after irradiation (cisplatin, vincristine, and lomustine) did not correlate with improved outcome. ${ }^{54}$ The SFOP demonstrated that chemotherapy (composed of carboplatin/procarbazine, etoposide/cisplatin, or vincristine/cyclophosphamide) without radiation is not sufficient for the treatment of sPNET and that foregoing radiation therapy worsens outcome. ${ }^{55}$ Duke University treated 6 children and 6 adults with pineoblastoma with cyclophosphamide-based induction chemotherapy, radiotherapy, and high-dose chemotherapy with cyclophosphamide and busulfan or mephalan followed by ASCR. Ten of 12 patients received craniospinal irradiation (36 Gy) and a local boost to the pineal area (range, 55.2 to $66 \mathrm{~Gy}$ ). At a median follow-up of 62 months, nine patients were alive including three patients with metastatic disease and two infants who never received radiation therapy. The authors concluded that high-dose chemotherapy is effective in patients with pineoblastoma and should especially be considered as initial treatment in infants and patients with metastatic disease. ${ }^{58}$ The PNET 3 study enrolled 68 patients with sPNET. These patients were treated with either a combination of chemotherapy (vincristine, etoposide, carboplatin, and vincristine, etoposide and cyclophosphamide) and radiation therapy (44 patients) or just radiation therapy (24 patients). The 3-year and 5-year OS in the combination group was $52.3 \%$ and $45 \%$ respectively, compared with a 3-year and 5-year OS of $58.3 \%$ and $54.2 \%$, respectively, in patients just treated with radiation therapy. ${ }^{59} \mathrm{~A}$ combined analysis of 17 patients enrolled in the CCG 9883 and MSKCC-89-173 trials investigated high-dose chemotherapy (combination of thiotepa, etoposide, with or without carboplatin) with ASCR specifically for patients with recurrent sPNET. Ten patients experienced tumor relapse at a median of 160 days after ASCR and died. Almost all surviving patients (4 of 5) underwent radiation therapy and had no evidence of measurable tumor prior to irradiation. Given the small sample size, it is impossible to determine which treatment contributed in these patients to their favorable outcome. ${ }^{60}$ The Head Start I and II protocols investigated the role of intensive chemotherapy with ASCR in patients with newly diagnosed sPNET (43 patients). The 5 -year OS was $49 \%$. Over half of the surviving patients (12 of 20) remain alive without radiation exposure and 15 of 20 had no craniospinal irradiation. ${ }^{61}$ Again, given the two different treatment regimens in these two protocols it remains difficult to answer which part of the therapy was most beneficial. Chintagumpala et al. ${ }^{62}$ investigated the use of reduced craniospinal irradiation (23.4 Gy) and high-dose chemotherapy with ASCR in children with nonmetastatic sPNET. In this study, patients with high-risk disease (defined as having either residual tumor $>1.5 \mathrm{~cm}^{2}$ or evidence of metastatic disease) received 36.0 to $39.6 \mathrm{~Gy}$, and those with average risk disease only 23.4 Gy to the craniospinal axis. Highdose chemotherapy consisted of four cycles of cyclophosphamide, cisplatin, and vincristine. Of 16 patients, 12 are alive at a median follow-up of 5.4 years. The- 5 year EFS estimates were reported for average diseaserisk patients at $75 \%( \pm 17 \%)$ and for high-risk patients at $60 \%( \pm 19 \%)$. These results are comparable with other studies and suggest that reduced craniospinal irradiation in combination with chemotherapy in averagerisk patients might not compromise outcome. ${ }^{62}$

The information available today suggests that SPNETs are chemo-sensitive and that high-dose chemotherapy can be successfully used in newly diagnosed sPNET. Especially younger children $(<3$ years of age $)$ might benefit from high-dose chemotherapy with ASCR as initial therapy to delay radiation therapy.

\section{Future directions for medulloblastoma/sPNET}

Major advances have been accomplished over the last few years especially for children with average risk medulloblastoma. Comparison between treatment trials, however, remains challenging, given the heterogeneity 
Table 1. Summary of Clinical and Molecular Markers Associated with Poor and Favorable Outcome in Medulloblastoma

\begin{tabular}{lll}
\hline & \multicolumn{1}{c}{ Poor Outcome } & \multicolumn{1}{c}{ Favorable Outcome } \\
\hline Clinical parameters & Age $<3$ years & Age $<3$ years \\
& Residual disease $>1.5 \mathrm{~cm}^{2}$ after resection & Complete resection \\
& Metastasis & \\
Molecular markers & 1q chromosome loss & TRK C expression \\
& 8q chromosome gain & Wnt/wingless pathway activation and loss of \\
& C-myc expression & Beta-catenin expression \\
& Erb B2 receptor expression & \\
& P53 expression & \\
& Survivin expression & \\
& EEF1D, RPL30, RPS 20 expression & \\
& OTX2 overexpression and amplification &
\end{tabular}

Erb B2 = epidermal growth factor receptor B2; EEF1D = eukaryotic translation elongation factor 1; RPL30 = ribosomal protein 130; RPS20 $=$ ribosomal protein $\mathrm{S} 20$.

of these tumors, especially for sPNET. Advances in understanding the molecular profile and associated clinical outcome will eventually lead to better risk stratification and enable treating neuro-oncologists to better determine risk-benefit profiles for each individual patient. The benefit of gene expression analysis of tumors to predict clinical outcome has already been established. ${ }^{63}$ Further, several markers have been linked to prognosis (Table 1). For example activation of the Wnt/beta catenin pathway and high expression of tyrosine receptor kinase $\mathrm{C}$ is associated with favorable outcome, ${ }^{64-67}$ whereas c-myc expression has been linked to poor outcome in multiple studies for patients with medulloblastoma. ${ }^{68-71}$ Overexpression of the homebox gene OTX2 is associated with anaplastic histological features in medulloblastoma, which is amplified in a subset of medulloblastomas. ${ }^{72}$ Integration of molecular studies in larger multicenter trials will be pivotal to enhance our understanding and to identify new therapeutic targets. To date, very little is known about the molecular biology of sPNET, but several key signaling pathways have been identified in medulloblastomas. These include the wingless, sonic Hedgehog and Notch pathways. Inhibition of these signaling cascades with small molecules led in different in vivo and in vitro models to regression of tumors and represent new attractive therapeutic avenues. ${ }^{73-75}$ More recently it appears the activation of the phosphatidylinositol-3-kinase pathway might be associated with medulloblastomas. Therefore, phosphatidylinositol-3kinase inhibitors may be attractive candidates in the treatment of these tumors. ${ }^{76-78}$ Preclinical studies have shown that retinoic acid (RA) has anticancer activity in a variety of cancers and is commonly used in acute promyelocytic leukemia and high-risk neuroblastoma. In vitro studies have shown that RA can also induce apoptosis in medulloblastoma cell lines. ${ }^{79}$ Subsequently, in vivo studies have demonstrated that a combination of RA with the histone deacetylase inhibitor suberoylanilide hydroxamic acid is effective in medulloblastoma xenografts as well as in trans- genic mice. ${ }^{80}$ Currently, RA is tested in clinical studies for children with medulloblastoma (Table 2).

The main goal for patients with average-risk disease is to improve morbidity of current treatment regimens and maintain adequate survival. Ongoing studies aim to reduce the amount of radiation exposure by using different radiation regimens like hyperfractionated accelerated radiation therapy and proton beam therapy in combination with chemotherapy including ASCR. For patients with high-risk and recurrent disease, survival remains poor; therefore, improving outcome is the focus of current investigations. Currently, different combinations of chemotherapy as well as radiation therapies are being tested. Newer approaches including intrathecal radio-immunotherapy and different small molecule inhibitors are also of exploratory interest. Table 2 lists a selection of ongoing clinical trials for newly diagnosed patients and patients with recurrent/refractory disease.

\section{Astrocytomas}

Astrocytomas are the most common subtype of pediatric brain tumors representing more than $50 \%$ of all tumors. The World Health Organization (WHO) classifies these tumors into low-grade (grade I-II) and highgrade (grade III-IV) tumors. Largely, the cause remains unknown, although some genetic disorders such as neurofibromatosis 1 or Li-Fraumeni syndrome carry a higher risk to develop these tumors. Prior radiation to the brain also remains a known risk factor. The outcome is correlated with histological grade, and survival remains poor in patients with high-grade astrocytomas.

\section{High-grade astrocytomas}

Introduction. High-grade gliomas are classically divided into WHO grade III tumors of anaplastic astrocytomas, WHO grade IV tumors of glioblastoma multiforme (GBM), and WHO grade III tumors of anaplastic oligodendroglial or mixed astrocytic tumors, which are less commonly found in children. High-grade gliomas 
Table 2. Ongoing Clinical Trials for Patients with Newly Diagnosed or Refractory/Recurrent Medulloblastoma/sPNET

\begin{tabular}{|c|c|c|c|c|c|}
\hline Indication/Goal & Phase & $\begin{array}{l}\text { Conventional } \\
\text { Chemotherapy }\end{array}$ & $\begin{array}{l}\text { Radiation } \\
\text { Therapy }\end{array}$ & $\begin{array}{l}\text { Investigational } \\
\text { Agent }\end{array}$ & Molecular Biology \\
\hline \multicolumn{6}{|l|}{ Newly diagnosed medulloblastoma/sPNET } \\
\hline $\begin{array}{l}\text { Two different RT regimens in combination } \\
\text { with ASCR }\end{array}$ & III & $\begin{array}{l}\text { CS, CP, V with } \\
\text { ASCR }\end{array}$ & $\begin{array}{l}+ \text { two different } \\
\text { RT regimens }\end{array}$ & - & $\begin{array}{l}\text { Erb B2 expression } \\
\text { protein/mRNA } \\
\text { expression }\end{array}$ \\
\hline Low-dose RT with chemotherapy & II & $\begin{array}{l}\mathrm{CS}, \mathrm{CP}, \mathrm{ET} \\
\quad \mathrm{L}, \mathrm{V}\end{array}$ & CIS 18 Gy & - & 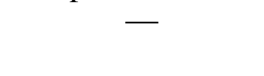 \\
\hline $\begin{array}{l}\text { Low-dose RT compared with standard dose } \\
\text { RT with combination chemotherapy }\end{array}$ & III & $\mathrm{CS}, \mathrm{CP}, \mathrm{L}, \mathrm{V}$ & $\begin{array}{l}\text { CIS } 18 \text { Gy vs } \\
\text { standard; } \\
\text { tumor boost vs } \\
\text { posterior fossa }\end{array}$ & - & - \\
\hline $\begin{array}{l}\text { Compare different chemotherapy regimens } \\
\text { prior to ASCR in children }<36 \text { month }\end{array}$ & III & $\begin{array}{l}\mathrm{CB}, \mathrm{CS}, \mathrm{CP}, \mathrm{E} \\
\mathrm{T}, \mathrm{V}, \mathrm{MTX}\end{array}$ & - & - & - \\
\hline Proton beam radiation & II & - & $\begin{array}{l}\text { Proton beam CSI } \\
\text { and posterior } \\
\text { fossa }\end{array}$ & - & - \\
\hline $\begin{array}{l}\text { Different chemotherapy and radiation } \\
\text { therapy regimens }\end{array}$ & III & $\mathrm{CB}, \mathrm{CS}, \mathrm{CP}, \mathrm{V}$ & Standard XRT & Isotretinoin & - \\
\hline $\begin{array}{l}\text { Radioimmunotherapy, reduced-dose EB- } \\
\text { CSI with IMRT boost and chemotherapy }\end{array}$ & II & $\mathrm{CP}, \mathrm{L}, \mathrm{V}$ & $\begin{array}{l}\text { EB-CSI with } \\
\text { IMRT boost }\end{array}$ & $\mathrm{I}^{131} 3 \mathrm{FA}$ & - \\
\hline \multicolumn{6}{|l|}{ Recurrent/Refractory medulloblastoma/sPNET } \\
\hline Hedgehog antagonist (GDC-0449) & I & - & - & GDC-0449 & $\begin{array}{l}\text { Gene expression } \\
\text { analysis }\end{array}$ \\
\hline Notch Signaling inhibitor (MK 0752) & $\mathrm{I}$ & - & - & MK 0752 & - \\
\hline Angiogenesis inhibitor Bevacizumab & II & Irinotecan & - & Bevacizumab & - \\
\hline VEGF inhibitor Cediranib (AZD 2171) & $\mathrm{I}$ & - & - & $\begin{array}{l}\text { Cediranib } \\
\quad(\text { AZD 2171) }\end{array}$ & - \\
\hline
\end{tabular}

ASCR = autologous stem cell rescue; $\mathrm{CB}=$ carboplatin; $\mathrm{CP}=$ cyclophosphamide; $\mathrm{CS}=$ cisplatin; $\mathrm{CSI}=$ craniospinal irradiation; $\mathrm{E}=$ etoposide; EB-CSI = external beam CSI; Erb B2 = epidermal growth factor receptor B2; IMRT = intensity modulated radiotherapy; $\mathrm{L}=$ lomustine; $\mathrm{RT}=$ radiation therapy; $\mathrm{SPNET}=$ supratentorial primitive neuroectodermal tumors; $\mathrm{V}=$ vincristine; VEGF = vascular endothelial growth factor.

make up the minority (up to 20\%) of supratentorial tumors in children. ${ }^{45}$ The 5 -year survival rate ranges from 5 to $15 \%$ for GBM and 20 to $40 \%$ for anaplastic astrocytomas. ${ }^{81}$ Diffuse brain stem gliomas are characteristically grade III or IV tumors and will be discussed separately as follows.

\section{Current treatment strategies}

Surgery. Surgical resection remains the cornerstone for the treatment of children with high-grade gliomas. Multiple studies have shown that the extent of resection is strongly linked to survival and therefore GTR is favored. ${ }^{82-85}$ For example, children with high-grade gliomas treated in the CCG 945 study who underwent GTR demonstrated a 5-year PFS of 35\% ( $\pm 7 \%$ ) compared with $17 \%( \pm 4 \%)$ in patients who underwent STR. ${ }^{84}$ This correlation was also found in the subgroup analysis of patients with anaplastic astrocytomas (GTR: 5-year PFS $44 \%$ [ $\pm 11 \%$ ] compared to STR: 5-year PFS $22 \%$ [ $\pm 6 \%]$ ), and GBM (GTR: 5-year PFS 26\% [ \pm 9\%] compared to STR: 5 -year PFS $4 \%[ \pm 3 \%]] .{ }^{84}$ However, one hallmark of high-grade gliomas is their infiltrative growth pattern that makes it difficult to obtain clear tumor boundaries. If the tumor extends into critical areas of the brain or crosses the midline, then an attempt should be made to remove as much tumor as is safely possible.

\section{Radiation}

Radiation therapy has been the standard of care for many years for patients with high-grade gliomas. It is generally recommended after surgery for children greater than 3 years of age. Studies have shown that most highgrade gliomas reoccur within a 2-cm margin of the original tumor location. Therefore, radiation is mainly aimed at the primary tumor site with a small margin. Common treatment regimens are composed of 50 to $60 \mathrm{~Gy}$ of external beam radiation delivered in daily fractions of 180 to $200 \mathrm{cGy}$. Higher radiation doses (to a cumulative total dose of $72 \mathrm{~Gy}$ ) in conjunction with hyperfractionation have failed to improve outcome for patients with high-grade gliomas. ${ }^{86}$

\section{Chemotherapy}

One of the first randomized trials (CCG 943) that investigated the role of chemotherapy in 72 children with high-grade gliomas was conducted by the CCG from 1976 until $1981 .^{87}$ The investigators reported a 5-year 
EFS of $46 \%$ in patients who received radiation and chemotherapy (nitrosourea, vincristine, and prednisone) compared with a 5-year EFS of $18 \%$ in patients who only underwent radiation therapy after surgical resection. ${ }^{87}$ Surprisingly, the effect of chemotherapy was strongest in patients with GBM. In this subgroup, 5-year EFS was $42 \%$ in the combined group compared with $6 \%$ in patients just receiving radiation therapy. ${ }^{87} \mathrm{~A}$ subsequent large phase III study (CCG 945) showed that a more intense chemotherapy with the "8-in-one-day" regimen versus the prior tested regimen with lomustine, vincristine, and prednisone had no beneficial effect on survival. Further analysis of the CCG-945 study showed that a significant number of patients were misclassified by institutional review and revised by a consensus neuropathology review as low-grade tumors. ${ }^{88,89}$ This is critical when assessing outcome of other treatment trials, and it highlights the importance of a central review process in pediatric gliomas. Since then, multiple trials investigated different chemotherapy regimens for the treatment of pediatric high-grade gliomas. The HIT-91 trial randomized children to either a sandwich therapy consisting of pre-irradiation chemotherapy (ifosfamide, VP-16, methotrexate, cisplatin, and cytarabine) followed by radiation therapy compared with radiation therapy followed by chemotherapy (lomustine, vincristine, and cisplatin). The multivariate analysis showed that pre-radiation chemotherapy, grade III tumors, and GTR (defined as $>90 \%$ resection) were associated with improved survival. The median OS was 5.17 years for the sandwich arm compared with 1.94 years for the maintenance arm. ${ }^{85}$ In the CCG-9933 study, the investigators compared three different alkylating agents (carboplatin, ifosfamide, and cyclophosphamide) administered in conjunction with etoposide in patients with residual disease. Unfortunately, none of the three treatment arms showed beneficial effect toward survival. ${ }^{90}$ The SFOP treated high-grade glioma patients with limited success with a combination of carmustine, cisplatin, and etoposide after surgery. The 5and 10-year OS were reported at $16 \%( \pm 9 \%)$ and $13.3 \%$ ( $\pm 9.4 \%)$, respectively. ${ }^{91}$ Concomitant TMZ and radiation therapy is the current standard for adult GBM patients. Multiple studies tested the response of pediatric high-grade gliomas and recurrent high-grade gliomas to TMZ with limited success. ${ }^{92-94}$ The difference in response to TMZ highlights the fact that pediatric highgrade gliomas are biologically different from their adult counterpart, despite similar histology. To date, most children with high-grade gliomas are enrolled in clinical trials, and the most effective chemotherapy regimen still needs to be established.

\section{Future directions}

Adult high-grade gliomas have been intensely studied, and key molecular pathways (e.g., the epidermal growth factor receptor [EGFR] pathway) have been identified to play a major role in the tumorigenesis of these tumors. Furthermore, targeted therapy against angiogenesis with, for example, bevacizumab (an antibody directed against vascular endothelial growth factor [VEGF]), has shown encouraging results in adult gliomas. ${ }^{95}$ Our current knowledge about key signaling cascades involved in pediatric gliomas remains limited. Inhibitors of EGFR or platelet-derived growth factor receptor are tested in phase I/II trials with and without radiation, as well as in combination with conventional chemotherapy. Erlotinib, an EGFR inhibitor, has recently been tested in a phase I trial in combination with radiation. One-year PFS was reported at $56 \%( \pm 10 \%)$ and 2-year PFS at $40 \%( \pm$ $13 \%) .{ }^{96}$ A recent phase I study from COG showed that the combination of erlotinib and TMZ is safe in children, and further studies are needed to assess tumor response. ${ }^{96}$ Imatinib, a platelet-derived growth factor receptor inhibitor, has been associated in a phase I trial with increased incidence of intracranial hemorrhage, especially in patients with brainstem gliomas. Although survival analysis was not primary objective of that study, estimates of PFS was not superior to other studies. ${ }^{97}$ Other small molecule inhibitors currently under investigation include inhibitors of the farnesyltransferase (lonafarnib), Notch (MK 0752) and mammalian target of rapamycin ([mTOR] temsirolismus, everolismus) signaling pathways as well as anti-angiogenic agents like bevacizumab. These agents are tested as single agent, as well as in combination with conventional chemotherapy and radiation. Antibody- or ligand-mediated targeting of tumor cells, vaccine therapy, and radionuclide conjugates specifically designed to bind directly to tumor cells are other avenues, which are currently explored for the treatment of high-grade gliomas.

\section{Low-grade astrocytomas}

Introduction. Low-grade astrocytomas account for approximately $40 \%$ of all childhood CNS tumors. Histologically low-grade gliomas are mainly classified into pilocytic astrocytomas (WHO grade I, also known as juvenile pilocytic astrocytoma) and fibrillary astrocytomas (WHO grade II), although other subgroups (such as gemistocytic astrocytomas or pleomorphic xantho-astrocytoma) have also been described. The most common location for juvenile pilocytic astrocytoma is the cerebellar hemispheres. Cerebellar astrocytomas present 20 to $35 \%$ of all posterior fossa tumors. The majority of these tumors (80\%) are juvenile pilocytic astrocytomas, followed by grade II (15\%) tumors. Other subtypes based on location are hemispheric, optic pathway, and thalamic lesions with distinct clinical features. Overall these tumors have a very good prognosis with 5-year OS rates of 80 to $90 \%$. 


\section{Current treatment strategies for low-grade astrocytomas}

Surgery. The first line treatment for children with low-grade gliomas is GTR. The extent of resection is strongly correlated with survival. ${ }^{98-100}$ In one series 10 year PFS was $100 \%$ in patients with GTR compared with only $67 \%$ in patients with STR. ${ }^{99}$ With the introduction of neuro-navigation systems, functional brain mapping via functional MRI, positron emission tomography, magnetoencephalography (an imaging technique that measures noninvasively the electrical activity in the brain that can be overlaid with MRI images), and cortical mapping, even lesions located in eloquent brain areas become more accessible for resection with minimal surgical morbidity. Given the relative indolent course of most low-grade gliomas, residual tumors are often followed by serial imaging. Second-look surgery is a viable option in case of recurrence or progression. ${ }^{99,101,102}$ Cerebellar astrocytomas, mainly consisting of grade I and II astrocytomas histologically, are curable by GTR. Recurrence-free survival is greater than $95 \%$ at 10 and 20 years. ${ }^{103}$ Many childhood low-grade gliomas extent to deep midline structures, which makes a GTR extremely difficult and are therefore associated with worse outcome. ${ }^{103}$ A common tumor in patients with neurofibromatosis 1 is a low-grade glioma of the optic pathways. Several studies have shown that optic pathway gliomas in neurofibromatosis 1 patients have a more indolent course and can be followed with serial imaging only. Surgical resection is not indicated in most cases unless there is evidence of tumor progression. ${ }^{104}$

\section{Radiation}

Generally patients with low-grade gliomas who undergo complete resection are not treated with adjuvant therapy until there is evidence of disease recurrence or progression on surveillance imaging. Patients treated on the CCG 945 trial, who were subsequently re-classified as low-grade tumors, showed a 5-year PFS of $68 \%$ ( \pm $6 \%)$ when treated with radiation therapy in conjunction with chemotherapy compared with only $38 \%( \pm 12 \%)$ when undergoing just chemotherapy. OS however, was not significantly affected by radiation therapy (5-year OS for chemo-radiotherapy group $79 \%[ \pm 3 \%]$, compared with $77 \%$ [ $\pm 10 \%]$ for the chemotherapy-only group). ${ }^{105}$ The experience at University of California, San Francisco demonstrated that upfront radiation therapy for patients with grade II gliomas did not improve survival, even in the setting of STR. This retrospective analysis of 90 patients revealed again the importance of the extent of resection on OS. ${ }^{106}$ Stereotactic radiation for localized disease has also been studied. One study demonstrated a 5-year OS of $97.7 \%$ and 8-year OS of $82 \%$ for children treated with stereotactic radiation therapy after evidence of recurrence or progression on chemotherapy or just after surgery alone. ${ }^{107}$ To date, the role of radiation in the treatment of low-grade gliomas has not been established and further studies are indicated.

\section{Chemotherapy}

Chemotherapy has been used for many years in different regimens for the treatment of patients with low-grade gliomas after subtotal resection or evidence of progressive disease. The heterogeneity of this tumor group, however, makes it difficult to compare results. In 1993, Packer et al. ${ }^{108}$ reported a radiographic response in 52\% of patients with recurrent disease and $62 \%$ in newly diagnosed patients treated with vincristine and carboplatin. These results were reproducible in a larger follow-up study of patients with newly diagnosed tumors. ${ }^{109}$ Currently, vincristine in combination with carboplatin is the most commonly used multi-agent chemotherapy for children with low-grade gliomas and future trials will be judged against these results. ${ }^{110}$ Over one tenth of children treated with carboplatin and vincristine will develop allergic reactions to carboplatin that often require cessation of therapy, and therefore new reagents are under investigation. ${ }^{108}$ Patients with recurrent or progressive low-grade gliomas treated with cisplatin and etoposide showed an objective response rate in $70 \%$ (24 of 34 patients). ${ }^{11}$ TMZ has been tested in pediatric low-grade glioma with moderate success. ${ }^{12,113}$ One study treated 30 children with progressive or recurrent low-grade gliomas with TMZ orally on 5 consecutive days (dose, 200 $\mathrm{mg} / \mathrm{m}^{2}$ ). Treatment cycles were repeated every 28 days and ranged from 2 to 12 cycles. The majority of patients in this study (19 of 30) were treated with chemotherapy and/or radiation therapy prior to enrollment. The 4-year PFS and OS were $17 \%$ (95\% CI, 1 to $33 \%$ ) and $71 \%$ (95\% CI, 43 to $100 \%$ ), respectively. Partial or minimal response was only observed in $12 \%$ of the patients. Only 9 patients $(30 \%)$ had stable disease and did not require any additional treatment after TMZ therapy. Eighteen patients required salvage therapy. The outcome compares unfavorably to prior reports as previously outlined. ${ }^{58}$ Ongoing studies are currently investigating the best chemotherapy regimen for these patients.

\section{Future directions for low-grade gliomas}

Genetic alterations frequently observed in adult anaplastic astrocytomas and/or glioblastomas, such as mutations of TP53 or PTEN, homozygous deletion of $C D K N 2 A$, amplification of CDK4 or EGFR, and losses of chromosome 10 , are only rarely encountered in pediatric pilocytic and low-grade diffuse astrocytomas. ${ }^{114}$ Most of these low-grade gliomas in children also show no significant change in copy number and have normal karyotypes, ${ }^{115-117}$ but one consistent finding between studies was the identification of trisomy of chromosome 5 and 7 or gains of 1q. ${ }^{117-119}$ The mitogen-activated protein kinase pathway activation in low-grade gliomas 
has been described in several studies and recently linked to duplication of the BRAF gene locus. ${ }^{120}$ Thus, aberrant mitogen-activated protein kinase signaling appears to be of importance in the pathogenesis of low-grade astrocytomas, and pharmacological inhibition of this pathway may constitute a promising new approach in the treatment of these tumors. ${ }^{120-122}$

Given the relative benign nature of low-grade gliomas and good OS, the focus of current studies is to avoid morbidities from medical treatment. Therefore, the goal is to minimize radiation exposure especially in young children due to the known adverse side effects. The best treatment strategy for recurrent or progressive low-grade gliomas is still under investigation, and currently different chemotherapy and radiation regimens are tested in clinical trials as listed in Table 3. The heterogeneity of low-grade gliomas makes interpretation of these studies difficult, and further attention needs to be directed in identifying key genetic and molecular characteristics.

\section{Diffuse brain stem glioma}

Introduction. Diffuse brainstem gliomas account for 58 to $75 \%$ of all pediatric brainstem tumors. They are characteristically malignant fibrillary astrocytomas (WHO grades III and IV), although other entities have been reported. ${ }^{123-126}$ The long-term survival is very poor with only 6 to $10 \%$ of patients surviving beyond 2 years of age, which has not changed over the last decades. ${ }^{127}$ Historical control data are relatively homogeneous among several trials and reveal 1-year OS of 30\% ( \pm $3 \%)$ and 1 -year PFS of $12 \%( \pm 2 \%)$, which against new therapeutics avenues will be tested. ${ }^{128}$

\section{Current treatment strategies}

Surgery. Surgical intervention has a limited role in the management of diffuse brainstem gliomas because MRI is generally sufficient to establish the diagnosis, ${ }^{129}$ and meaningful resection remains impossible due to the diffuse infiltration of the tumor in surrounding brainstem structures. ${ }^{130}$ A biopsy can be performed safely if needed, but often does not alter the therapeutic approach and is generally not recommended. ${ }^{124}$ For example, the CCG investigated the role of biopsy in a total of 120 children with diffuse brainstem gliomas. Of these, 45 children underwent biopsy with pathology available in 36 cases (low-grade astrocytoma [13], anaplastic astrocytoma [20], GBM [2], nondiagnostic [1]). Regardless of pathology or whether a biopsy was performed, all patients had a poor outcome. ${ }^{131}$ To date, most centers diagnose children with diffuse brain stem gliomas based on characteristic MRI findings in the right clinical scenario without tissue diagnosis.

\section{Radiation}

Radiotherapy remains the cornerstone for the treatment of diffuse brain stem glioma, but it is not curative. Most patients show an initial response to therapy, but usually within a few months the tumor progression occurs. Multiple studies investigated the benefit of escalating the radiation dose through hyperfractionation with disappointing results. The POG compared doses up to 7560 cGy and demonstrated that there was no significant survival benefit with higher doses of radiation. ${ }^{132}$ The CCG used 7,800 cGy and found similar results. ${ }^{131} \mathrm{Ra}-$ diosensitizing agents like cisplatin have been tested with conventional versus hyperfractionated accelerated radiation therapy with no survival benefit for the latter group. ${ }^{133}$ The current standard of care for diffuse brainstem gliomas is conventional radiotherapy with a local field dose of 5,400 to 6,400 cGy in 6 weeks in $180 \mathrm{cGy}$ daily fractions, but outcome remains poor.

\section{Chemotherapy}

Given the dismal outcome for patients with diffuse brainstem glioma, many studies have investigated the role of different chemotherapy regimens for the treatment of these patients, but currently the added benefit remains a subject of debate. One study conducted by the CCG compared the effect of irradiation with and without two different adjuvant chemotherapy regimens composed of carboplatin, etoposide, vincristine or cisplatin, etoposide, cyclophosphamide, and vincristine. There was no significant improvement with the addition of either chemotherapy regimen. ${ }^{134}$ The POG demonstrated that children treated with radiation therapy alone had similar outcome to patients treated with radiation and cisplatin. ${ }^{135}$ Marrow ablative chemotherapy with ASCR has been investigated in patients newly diagnosed or with

Table 3. Selection of Ongoing Clinical Trials for Children with Low-Grade Gliomas

\begin{tabular}{|c|c|c|c|c|c|}
\hline Indication & Phase & $\begin{array}{l}\text { Conventional } \\
\text { Chemotherapy }\end{array}$ & Radiation Therapy & $\begin{array}{l}\text { Investigational } \\
\text { Agent }\end{array}$ & $\begin{array}{c}\text { Molecular } \\
\text { Biology }\end{array}$ \\
\hline Progressive LGG & II & Vinblastine & - & - & - \\
\hline Progressive LGG & II & Everolismus & - & - & - \\
\hline Progressive LGG to assess RT versus CT & III & $\mathrm{CB}, \mathrm{CS}, \mathrm{E}, \mathrm{V}$ & RT & - & - \\
\hline Progressive LGG & I/II & Irinotecan & - & Erlotinib & EGFR \\
\hline LGG & III & - & $\begin{array}{l}\text { Stereotactic vs. } \\
\text { conventional RT }\end{array}$ & - & - \\
\hline
\end{tabular}

$\mathrm{CT}=$ chemotherapy; EGFR $=$ epidermal growth factor receptor; $\mathrm{LGG}=$ low-grade glioma; $\mathrm{RT}=$ radiation therapy . 
recurrent disease with no significant benefit on survival, but with significant toxicities. ${ }^{136-138}$ Most recently a small study assessed the benefit of neoadjuvant chemotherapy (cisplatin, methotrexate) to delay radiation therapy until time of progression. The results were compared with a historical cohort and demonstrated a median survival of 17 months in the treatment group compared with 9 months in the control group, but therapy was associated with significant toxicity and prolonged hospitalizations. ${ }^{139}$ TMZ in combination with cis-retinoic acid and radiation therapy has been tested in a small number of patients with brain stem glioma with limited success and a reported median survival of 13.5 months $( \pm 3.6$ months). ${ }^{140}$ One difficulty in assessing the benefit of different chemotherapy regimens is the inconsistency between trials regarding eligibility criteria, assessment of tumor progression, and different endpoints. However, despite this variability, no improvement in survival has been documented for the last 30 years. ${ }^{141}$ Because the outcome has not been changed, despite multiple different avenues investigated, these patients should be considered for phase I trials whenever possible.

\section{Future directions}

Progress in the development of effective therapies for diffuse brainstem glioma is compromised by the unavailability of tissue samples and the lack of noninvasive markers that can characterize disease status. Conventional MRI has been shown to be insufficient in predicting clinical outcome. ${ }^{142}$ The limited information currently available on molecular pathways involved in the tumorigenesis of these tumors limits a rational approach to test new agents. To date, new trials are often designed based on knowledge gained from other adult or pediatric high-grade glioma experiences. Inhibitors of EGFR (e.g., gefitinib or erlotinib) have been tested in diffuse brain stem gliomas in small series with minimal success. ${ }^{143,144}$ Inhibition of angiogenesis is another focus of current investigations. Bevacizumab showed promising results in adult patients with high-grade glioma, and is currently studied in pediatric brainstem gliomas. ${ }^{95}$ Other anti-angiogenic agents currently under investigation include the oral VEGF inhibitor AZD2171. Another research area is the delivery of agents to the tumor, either by catheterbased technologies, such as convection-enhanced delivery, or with the use of small molecules interrupting the blood brain barrier. ${ }^{145}$

\section{Ependymoma}

Introduction. Ependymoma is the third most common pediatric brain tumor after astrocytomas and medulloblastomas. The peak incidence is between birth and 4 years of age.

Currently, ependymomas are classified by the WHO as grade I (myxopapillary), grade II (cellular, papillary, clear cell, and tancytic), and grade III (anaplastic), al- though clinical studies have failed to show a correlation between grade and overall outcome. ${ }^{146}$ The high variability among neuropathologists with reported discordance of $69 \%$ between central and local review remains a challenge in developing new therapeutics and assess the response rates in different clinical trials. ${ }^{147,148}$ In a recent analysis of a population-based registry, 5-year OS was reported to be $57.1 \%$ ( $\pm 2.3 \%$ ). Infratentorial location was associated with improved 5-year OS $(86.7 \% \pm$ $5.2 \%$ ) compared with supratentorially located tumors (5year OS $59.5 \%[ \pm 5.5 \%]) .{ }^{149}$

\section{Current treatment strategies}

Surgery. Surgical resection remains the mainstay of initial management and multiple studies have linked outcome to the extent of resection. ${ }^{148,150}$ The German HIT trial demonstrated that the only two significant prognostic factors were the extent of resection with a 3-year PFS of $83.3 \%$ after GTR compared to $38.5 \%$ after STR, as well as the presence of metastases at the time of diagnosis. ${ }^{150}$ In a prior study, patients undergoing GTR had a 5-year PFS of $66 \%$ compared with $11 \%$ without complete resection. ${ }^{148}$ Second-look surgery should be considered in patients with residual disease because the majority of recurrence occurs at the primary tumor site.

\section{Radiation therapy}

Radiation therapy is considered by many the standard of care for intracranial ependymomas in children older than 3 years of age. Multiple studies have shown adequate control with radiation targeted to the initially involved area. ${ }^{151-153}$ The experience from St. Jude's hospital demonstrated a 3-year PFS of $69.5 \%$ in a phase II trial using conformal radiotherapy in 88 children with ependymoma $(55 \%<3$ years of age). Serial neurocognitive evaluations demonstrated no significant decline before and after radiation therapy independent of age. ${ }^{152}$ A recent study reported promising results using proton beam radiation for patients with ependymomas. The major aim using proton radiotherapy is to reduce the amount of radiation exposure to normal brain. This is mainly achieved by elimination of exit dose and reduction of entrance dose. A total of 17 patients were evaluated and at a median follow-up of 26-month PFS reported at $80 \%$ $( \pm 10 \%)$ and OS at $89 \%( \pm 10 \%) .{ }^{154}$ The follow-up of this study is too short to determine the effect on longterm outcome. Prophylactic spinal irradiation did not seem to modify outcome in multiple series and should be reserved for patients with evidence of spinal seeding, and might be considered in patients with infratentorial anaplastic ependymomas. ${ }^{155,156}$ Radiosurgery is a potential treatment option for patients with recurrent disease. In one study local tumor control was achieved in 3 of 5 patients treated for localized residual ependymoma. ${ }^{157} \mathrm{~A}$ phase I study also demonstrated that intraoperative radiotherapy with photon radiosurgery might be an alter- 
native treatment strategy for patients with recurrent disease. Of 14 patients (13 diagnosed with recurrent ependymoma), 8 (57\%) showed local tumor control after surgical resection and intraoperative radiotherapy. ${ }^{158}$ With the development of these new radiation techniques, the effect on cognition and development might be reduced and therefore become a valid part in the treatment of these patients, independent of age.

\section{Chemotherapy}

The role of chemotherapy in the treatment of ependymomas remains controversial. Given the relatively high number of patients who are less than 3 years of age at time of diagnosis, multiple studies have investigated the role of chemotherapy to delay irradiation and avoid the associated side effects. A study from the United Kingdom Cancer study group and International Society of Pediatric Oncology treated children less than 3 years of age with combined adjuvant chemotherapy (carboplatin, vincristine, cyclophosphamide, cisplatin, and methotrexate). Radiation therapy was reserved for patients with recurrent resistant disease. The authors reported a 3-year PFS of $69.5 \%$, but 34 of 50 patients who had evidence of progression underwent subsequently radiotherapy. ${ }^{159}$ These findings are better than prior reports from the POG, who treated patients from 1986 until 1990 with 12 or 24 months of chemotherapy prior to radiation with a disappointing 5-year PFS of 27\%. ${ }^{160}$ The French oncology group reported a 4-year PFS of $22 \%$ in 73 patients treated with chemotherapy only. ${ }^{161}$ The CCG 9921 study assessed the effect of two different chemotherapy regimens in 74 children less than 3 years of age to estimate control intervals without irradiation. ${ }^{41}$ Chemotherapy consisted of induction chemotherapy with vincristine, cisplatin, etoposide, and cyclophosphamide, or vincristine, carboplatin, ifosfamide, and etoposide. Maintenance chemotherapy was the same in the two treatment arms and compromised vincristine, etoposide, carboplatin, and cyclophosphamide. Radiation therapy was delayed in children with no residual or metastatic disease, unless they progressed. There was no significant difference between the two treatment arms. The 1- and 5-year
PFS were $72 \%( \pm 5 \%)$ and $32 \%( \pm 6 \%)$, respectively for patients diagnosed with ependymoma. Five-year OS was $59 \%( \pm 6)$ and $63 \%$ of the 5-year event-free survivors had not received radiation therapy. ${ }^{41}$ Multiple agents including carboplatin, cisplatin, etoposide, idarubicin, ifosfamide, irinotecan, carmustine, and TMZ have been studied in phase II trials with modest response. ${ }^{162}$ Multi-agent strategies (e.g., lomustine, prednisone, and vincristine), ${ }^{163}$ as well as high-dose chemotherapy with stem cell rescue have been disappointing and can not be generally recommended. ${ }^{164}$ Chemotherapy to date is used as an adjuvant therapy in patients with residual or recurrent disease, but cannot be recommended as standard treatment.

\section{Future directions for ependymomas}

Molecular biology. Little is known regarding the molecular pathways involved in the development of ependymomas compared with other brain tumors. Loss of the tumor suppressor gene neurofibromatosis (NF) 2 on chromosome 22 has been frequently described in ependymomas. ${ }^{165-167} \mathrm{NF} 2$ is a key regulator of cell membrane/cytoskeleton-associated protein 4.1 super family. Other members of the same group (4.1 B and 4.1 R) have also been associated with ependymomas. ${ }^{168}$ Through comparative genomic hybridization and gene expression analysis, common pathways associated with the development of cancer have been associated with ependymomas like the Notch, sonic hedgehog, and EGFR/ phosphatidylinositol-3-kinase/Akt pathway. ${ }^{169-171} \mathrm{Re}-$ cent studies identified radial glial cells as the potential cancer stem cells of ependymomas. ${ }^{171,172}$ If the stem cell hypothesis holds true, it will be essential for further drug development in particular to address these cancer stem cells.

\section{Ongoing clinical trials}

Current studies are testing investigational agents, combination chemotherapy, and different radiation therapy regimens for patients with ependymomas (Table 4). The benefit of anti-angiogenesis therapy with antibodies directed against VEGF is under current investigation in

Table 4. Selection of Ongoing Clinical Trials for Children with Ependymomas

\begin{tabular}{|c|c|c|c|c|c|}
\hline Indication & Phase & $\begin{array}{l}\text { Conventional } \\
\text { Chemotherapy }\end{array}$ & Radiation Therapy & $\begin{array}{c}\text { Investigational } \\
\text { Agent }\end{array}$ & $\begin{array}{c}\text { Molecular } \\
\text { Biology }\end{array}$ \\
\hline $\begin{array}{l}\text { Recurrent/anaplasic } \\
\text { ependymoma }\end{array}$ & II & TMZ & - & Lapatinib & - \\
\hline Localized ependymoma & II & $\mathrm{CP}, \mathrm{E}, \mathrm{V}$ & If recurrent disease $+\mathrm{RT}$ & - & - \\
\hline Residual ependymoma & II & MTX & - & - & - \\
\hline $\begin{array}{l}\text { Ependymoma in children } \\
<3 \text { years of age }\end{array}$ & III & CB, CP, CS, MTX, V & When progression $+\mathrm{RT}$ & - & + \\
\hline Ependymoma & II & Irinotecan & - & Bevacizumab & - \\
\hline
\end{tabular}

$\mathrm{TMZ}=$ temozolamide. 
recurrent ependymomas. Only a limited number of studies to date include biological endpoints in the study protocol. Further characterization of the underlying signaling pathways will be important to develop new therapies and to better risk stratify patients with ependymoma.

\section{REFERENCES}

1. Kagawa N, Maruno M, Suzuki T, et al. Detection of genetic and chromosomal aberrations in medulloblastomas and primitive neuroectodermal tumors with DNA microarrays. Brain Tumor Pathol 2006;23:41-47.

2. Nicholson JC, Ross FM, Kohler JA, Ellison DW. Comparative genomic hybridization and histological variation in primitive neuroectodermal tumours. Br J Cancer 1999;80:1322-1331.

3. Pomeroy SL, Tamayo P, Gaasenbeek M, et al. Prediction of central nervous system embryonal tumour outcome based on gene expression. Nature 2002;415:436-442.

4. Russo C, Pellarin M, Tingby O, et al. Comparative genomic hybridization in patients with supratentorial and infratentorial primitive neuroectodermal tumors. Cancer 1999;86:331-339.

5. Albright AL, Wisoff JH, Zeltzer PM, et al. Effects of medulloblastoma resections on outcome in children: a report from the Children's Cancer Group. Neurosurgery 1996;38:265-271.

6. Grill J, Sainte-Rose C, Jouvet A, et al. Treatment of medulloblastoma with postoperative chemotherapy alone: an SFOP prospective trial in young children. Lancet Oncol 2005;6:573-580.

7. Zeltzer PM, Boyett JM, Finlay JL, et al. Metastasis stage, adjuvant treatment, and residual tumor are prognostic factors for medulloblastoma in children: conclusions from the Children's Cancer Group 921 randomized phase III study. J Clin Oncol 1999; 17:832-845.

8. Lee M, Wisoff JH, Abbott R, Freed D, Epstein FJ. Management of hydrocephalus in children with medulloblastoma: prognostic factors for shunting. Pediatr Neurosurg 1994;20:240-247.

9. Robertson PL, Muraszko KM, Holmes EJ, et al. Incidence and severity of postoperative cerebellar mutism syndrome in children with medulloblastoma: a prospective study by the Children's Oncology Group. J Neurosurg 2006;105:444-451.

10. Doxey D, Bruce D, Sklar F, Swift D, Shapiro K. Posterior fossa syndrome: identifiable risk factors and irreversible complications. Pediatr Neurosurg 1999;31:131-136.

11. Turgut M. Transient "cerebellar" mutism. Childs Nerv Syst 1998; 14:161-166.

12. Adachi J, Nishikawa R, Hirose T, Matsutani M. Mixed neuronalglial tumor of the fourth ventricle and successful treatment of postoperative mutism with bromocriptine: case report. Surg Neurol 2005;63:375-379.

13. Mateo-Sierra O, Gutierrez FA, Fernandez-Carballal C, et al. [Akinetic mutism related to hydrocephalus and cerebellar surgery treated with bromocriptine and ephedrine. A pathophysiological review]. Neurocirugia (Astur) 2005;16:134-141.

14. Grau C, Overgaard J. Postirradiation sensorineural hearing loss: a common but ignored late radiation complication. Int J Radiat Oncol Biol Phys 1996;36:515-517.

15. Plowman PN. Post-radiation sensorineuronal hearing loss. Int $\mathbf{J}$ Radiat Oncol Biol Phys 2002;52:589-591.

16. Merchant TE, Kiehna EN, Li C, et al. Modeling radiation dosimetry to predict cognitive outcomes in pediatric patients with CNS embryonal tumors including medulloblastoma. Int J Radiat Oncol Biol Phys 2006;65:210-221.

17. Ricardi U, Corrias A, Einaudi S, et al. Thyroid dysfunction as a late effect in childhood medulloblastoma: a comparison of hyperfractionated versus conventionally fractionated craniospinal radiotherapy. Int J Radiat Oncol Biol Phys 2001;50:1287-1294.

18. Bowers DC, Liu Y, Leisenring W, et al. Late-occurring stroke among long-term survivors of childhood leukemia and brain tumors: a report from the Childhood Cancer Survivor Study. J Clin Oncol 2006;24:5277-5282.
19. Neglia JP, Robison LL, Stovall M, et al. New primary neoplasms of the central nervous system in survivors of childhood cancer: a report from the Childhood Cancer Survivor Study. J Natl Cancer Inst 2006;98:1528-1537.

20. Deutsch M, Thomas PR, Krischer J, et al. Results of a prospective randomized trial comparing standard dose neuraxis irradiation $(3,600 \mathrm{cGy} / 20)$ with reduced neuraxis irradiation $(2,340 \mathrm{cGy} / 13)$ in patients with low-stage medulloblastoma. A Combined Children's Cancer Group-Pediatric Oncology Group Study. Pediatr Neurosurg 1996;24:167-176.

21. Thomas PR, Deutsch M, Kepner JL, et al. Low-stage medulloblastoma: final analysis of trial comparing standard-dose with reduced-dose neuraxis irradiation. J Clin Oncol 2000;18:30043011.

22. Merchant TE, Kun LE, Krasin MJ, et al. Multi-institution prospective trial of reduced-dose craniospinal irradiation (23.4 Gy) followed by conformal posterior fossa (36 Gy) and primary site irradiation $(55.8 \mathrm{~Gy})$ and dose-intensive chemotherapy for average-risk medulloblastoma. Int J Radiat Oncol Biol Phys 2008;70: 782-787.

23. Wolden SL, Dunkel IJ, Souweidane MM, et al. Patterns of failure using a conformal radiation therapy tumor bed boost for medulloblastoma. J Clin Oncol 2003;21:3079-3083.

24. Abe M, Tokumaru S, Tabuchi K, et al. Stereotactic radiation therapy with chemotherapy in the management of recurrent medulloblastomas. Pediatr Neurosurg 2006;42:81-88.

25. Hodgson DC, Goumnerova LC, Loeffler JS, et al. Radiosurgery in the management of pediatric brain tumors. Int J Radiat Oncol Biol Phys 2001;50:929-935.

26. Milker-Zabel S, Zabel A, Thilmann C, et al. Results of threedimensional stereotactically-guided radiotherapy in recurrent medulloblastoma. J Neurooncol 2002;60:227-233.

27. Packer RJ, Gajjar A, Vezina G, et al. Phase III study of craniospinal radiation therapy followed by adjuvant chemotherapy for newly diagnosed average-risk medulloblastoma. J Clin Oncol 2006;24:4202-4208.

28. Packer RJ, Goldwein J, Nicholson HS, et al. Treatment of children with medulloblastomas with reduced-dose craniospinal radiation therapy and adjuvant chemotherapy: A Children's Cancer Group Study. J Clin Oncol 1999;17:2127-2136.

29. Kortmann RD, Kuhl J, Timmermann B, et al. Postoperative neoadjuvant chemotherapy before radiotherapy as compared to immediate radiotherapy followed by maintenance chemotherapy in the treatment of medulloblastoma in childhood: results of the German prospective randomized trial HIT ' 91 . Int J Radiat Oncol Biol Phys 2000;46:269-279.

30. Taylor RE, Bailey CC, Robinson K, et al. Results of a randomized study of preradiation chemotherapy versus radiotherapy alone for nonmetastatic medulloblastoma: The International Society of Paediatric Oncology/United Kingdom Children's Cancer Study Group PNET-3 Study. J Clin Oncol 2003;21:1581-1591.

31. Taylor RE, Bailey CC, Robinson KJ, et al. Outcome for patients with metastatic (M2-3) medulloblastoma treated with SIOP/ UKCCSG PNET-3 chemotherapy. Eur J Cancer 2005;41: 727-734.

32. Okada S, Hongo T, Sakaguchi K, et al. Pilot study of ifosfamide/ carboplatin/etoposide (ICE) for peripheral blood stem cell mobilization in patients with high-risk or relapsed medulloblastoma. Childs Nerv Syst 2007;23:407-413.

33. Strother D, Ashley D, Kellie SJ, et al. Feasibility of four consecutive high-dose chemotherapy cycles with stem-cell rescue for patients with newly diagnosed medulloblastoma or supratentorial primitive neuroectodermal tumor after craniospinal radiotherapy: results of a collaborative study. J Clin Oncol 2001;19:26962704.

34. Gajjar A, Chintagumpala M, Ashley D, et al. Risk-adapted craniospinal radiotherapy followed by high-dose chemotherapy and stem-cell rescue in children with newly diagnosed medulloblastoma (St Jude Medulloblastoma-96): long-term results from a prospective, multicentre trial. Lancet Oncol 2006;7:813-820.

35. Jakacki R, Burger P, Zhou T, et al. Outcome for metastatic (M+) medulloblastoma (MB) treated with carboplatin during craniospinal radiotherapy (CSRT) followed by cyclophosphamide (CPM) 
and vincristine (VCR): Preliminary results of COG 99701. Journal of Clinical Oncology 2007;25:2017.

36. Evans AE, Jenkin RD, Sposto R, et al. The treatment of medulloblastoma. Results of a prospective randomized trial of radiation therapy with and without $\mathrm{CCNU}$, vincristine, and prednisone. J Neurosurg 1990;72:572-582.

37. Rutkowski S, Bode U, Deinlein F, et al. Treatment of early childhood medulloblastoma by postoperative chemotherapy alone. N Engl J Med 2005;352:978-986.

38. van Eys J, Cangir A, Coody D, Smith B. MOPP regimen as primary chemotherapy for brain tumors in infants. J Neurooncol 1985;3:237-243.

39. Duffner PK, Horowitz ME, Krischer JP, et al. Postoperative chemotherapy and delayed radiation in children less than three years of age with malignant brain tumors. N Engl J Med 1993;328: $1725-1731$.

40. Geyer JR, Zeltzer PM, Boyett JM, et al. Survival of infants with primitive neuroectodermal tumors or malignant ependymomas of the CNS treated with eight drugs in 1 day: a report from the Childrens Cancer Group. J Clin Oncol 1994;12:1607-1615.

41. Geyer JR, Sposto R, Jennings M, et al. Multiagent chemotherapy and deferred radiotherapy in infants with malignant brain tumors: a report from the Children's Cancer Group. J Clin Oncol 2005; 23:7621-7631.

42. Mason WP, Grovas A, Halpern S, et al. Intensive chemotherapy and bone marrow rescue for young children with newly diagnosed malignant brain tumors. J Clin Oncol 1998;16:210-221.

43. Chi SN, Gardner SL, Levy AS, et al. Feasibility and response to induction chemotherapy intensified with high-dose methotrexate for young children with newly diagnosed high-risk disseminated medulloblastoma. J Clin Oncol 2004;22:4881-4887.

44. Michaelis J, Kaletsch U, Kaatsch P. [Epidemiology of childhood brain tumors]. Zentralbl Neurochir 2000;61:80-87.

45. Pollack IF. Brain tumors in children. N Engl J Med 1994;331: $1500-1507$.

46. Johnston DL, Keene DL, Lafay-Cousin L, et al. Supratentorial primitive neuroectodermal tumors: a Canadian pediatric brain tumor consortium report. J Neurooncol 2008;86:101-108.

47. Chang $\mathrm{CH}$, Housepian EM, Herbert C, Jr. An operative staging system and a megavoltage radiotherapeutic technic for cerebellar medulloblastomas. Radiology 1969;93:1351-1359.

48. Albright AL, Wisoff JH, Zeltzer P, et al. Prognostic factors in children with supratentorial (nonpineal) primitive neuroectodermal tumors. A neurosurgical perspective from the Children's Cancer Group. Pediatr Neurosurg 1995;22:1-7.

49. Ashwal S, Hinshaw DB, Jr., Bedros A. CNS primitive neuroectodermal tumors of childhood. Med Pediatr Oncol 1984;12:180188.

50. Dirks PB, Harris L, Hoffman HJ, et al. Supratentorial primitive neuroectodermal tumors in children. J Neurooncol 1996;29: $75-84$.

51. MacDonald TJ. Aggressive infantile embryonal tumors. J Child Neurol 2008;23:1195-1204.

52. Reddy AT, Janss AJ, Phillips PC, Weiss HL, Packer RJ. Outcome for children with supratentorial primitive neuroectodermal tumors treated with surgery, radiation, and chemotherapy. Cancer 2000; 88:2189-2193.

53. Massimino M, Gandola L, Spreafico F, et al. Supratentorial primitive neuroectodermal tumors (S-PNET) in children: A prospective experience with adjuvant intensive chemotherapy and hyperfractionated accelerated radiotherapy. Int J Radiat Oncol Biol Phys 2006;64:1031-1037.

54. Timmermann B, Kortmann RD, Kuhl J, et al. Role of radiotherapy in the treatment of supratentorial primitive neuroectodermal tumors in childhood: results of the prospective German brain tumor trials HIT 88/89 and 91. J Clin Oncol 2002;20:842-849.

55. Marec-Berard P, Jouvet A, Thiesse P, et al. Supratentorial embryonal tumors in children under 5 years of age: an SFOP study of treatment with postoperative chemotherapy alone. Med Pediatr Oncol 2002;38:83-90.

56. McBride SM, Daganzo SM, Banerjee A, et al. Radiation is an important component of multimodality therapy for pediatric non- pineal supratentorial primitive neuroectodermal tumors. Int $\mathrm{J}$ Radiat Oncol Biol Phys 2008;72:1319-1323.

57. Jakacki RI, Zeltzer PM, Boyett JM, et al. Survival and prognostic factors following radiation and/or chemotherapy for primitive neuroectodermal tumors of the pineal region in infants and children: a report of the Childrens Cancer Group. J Clin Oncol 1995;13:1377-1383.

58. Gururangan S, McLaughlin C, Quinn J, et al. High-dose chemotherapy with autologous stem-cell rescue in children and adults with newly diagnosed pineoblastomas. J Clin Oncol 2003;21: 2187-2191.

59. Pizer BL, Weston CL, Robinson KJ, et al. Analysis of patients with supratentorial primitive neuro-ectodermal tumours entered into the SIOP/UKCCSG PNET 3 study. Eur J Cancer 2006;42: $1120-1128$

60. Broniscer A, Nicolaides TP, Dunkel IJ, et al. High-dose chemotherapy with autologous stem-cell rescue in the treatment of patients with recurrent non-cerebellar primitive neuroectodermal tumors. Pediatr Blood Cancer 2004;42:261-267.

61. Fangusaro J, Finlay J, Sposto R, et al. Intensive chemotherapy followed by consolidative myeloablative chemotherapy with autologous hematopoietic cell rescue (AuHCR) in young children with newly diagnosed supratentorial primitive neuroectodermal tumors (sPNETs): report of the Head Start I and II experience. Pediatr Blood Cancer 2008;50:312-318.

62. Chintagumpala M, Hassall T, Palmer S, et al. A pilot study of risk-adapted radiotherapy and chemotherapy in patients with supratentorial PNET. Neuro Oncol 2009;11:33-40.

63. Fernandez-Teijeiro A, Betensky RA, Sturla LM, et al. Combining gene expression profiles and clinical parameters for risk stratification in medulloblastomas. J Clin Oncol 2004;22:994-998.

64. Fattet S, Haberler C, Legoix P, et al. Beta-catenin status in paediatric medulloblastomas: correlation of immunohistochemical expression with mutational status, genetic profiles, and clinical characteristics. J Pathol 2009;218:86-94.

65. Grotzer MA, Janss AJ, Fung K, et al. TrkC expression predicts good clinical outcome in primitive neuroectodermal brain tumors. J Clin Oncol 2000;18:1027-1035.

66. Grotzer MA, Janss AJ, Phillips PC, Trojanowski JQ. Neurotrophin receptor TrkC predicts good clinical outcome in medulloblastoma and other primitive neuroectodermal brain tumors. Klin Padiatr 2000;212:196-199.

67. Segal RA, Goumnerova LC, Kwon YK, Stiles CD, Pomeroy SL. Expression of the neurotrophin receptor TrkC is linked to a favorable outcome in medulloblastoma. Proc Natl Acad Sci U S A 1994;91:12867-12871.

68. Eberhart CG, Kratz J, Wang Y, et al. Histopathological and molecular prognostic markers in medulloblastoma: c-myc, $\mathrm{N}$ myc, TrkC, and anaplasia. J Neuropathol Exp Neurol 2004;63: 441-449.

69. Grotzer MA, Hogarty MD, Janss AJ, et al. MYC messenger RNA expression predicts survival outcome in childhood primitive neuroectodermal tumor/medulloblastoma. Clin Cancer Res 2001;7: 2425-2433.

70. Herms J, Neidt I, Luscher B, et al. C-MYC expression in medulloblastoma and its prognostic value. Int J Cancer 2000;89:395402.

71. Rutkowski S, von Bueren A, von Hoff K, et al. Prognostic relevance of clinical and biological risk factors in childhood medulloblastoma: results of patients treated in the prospective multicenter trial HIT'91. Clin Cancer Res 2007;13:2651-2657.

72. Di C, Liao S, Adamson DC, et al. Identification of OTX2 as a medulloblastoma oncogene whose product can be targeted by all-trans retinoic acid. Cancer Res 2005;65:919-924.

73. Berman DM, Karhadkar SS, Hallahan AR, et al. Medulloblastoma growth inhibition by hedgehog pathway blockade. Science 2002;297:1559-1561.

74. Fan X, Matsui W, Khaki L, et al. Notch pathway inhibition depletes stem-like cells and blocks engraftment in embryonal brain tumors. Cancer Res 2006;66:7445-7452.

75. Romer JT, Kimura H, Magdaleno S, et al. Suppression of the SHH pathway using a small molecule inhibitor eliminates medul- 
loblastoma in Ptc1(+/-)p53(-/-) mice. Cancer Cell 2004;6: 229-240.

76. Guerreiro AS, Fattet S, Fischer B, et al. Targeting the PI3K p110alpha isoform inhibits medulloblastoma proliferation, chemoresistance, and migration. Clin Cancer Res 2008;14:67616769.

77. Hambardzumyan D, Becher OJ, Rosenblum MK, et al. PI3K pathway regulates survival of cancer stem cells residing in the perivascular niche following radiation in medulloblastoma in vivo. Genes Dev 2008;22:436-448.

78. Hartmann W, Digon-Sontgerath B, Koch A, et al. Phosphatidylinositol 3'-kinase/AKT signaling is activated in medulloblastoma cell proliferation and is associated with reduced expression of PTEN. Clin Cancer Res 2006;12:3019-3027.

79. Hallahan AR, Pritchard JI, Chandraratna RA, et al. BMP-2 mediates retinoid-induced apoptosis in medulloblastoma cells through a paracrine effect. Nat Med 2003;9:1033-1038.

80. Spiller SE, Ditzler SH, Pullar BJ, Olson JM. Response of preclinical medulloblastoma models to combination therapy with 13-cis retinoic acid and suberoylanilide hydroxamic acid (SAHA). J Neurooncol 2008;87:133-141.

81. Pollack IF, Finkelstein SD, Woods J, et al. Expression of p53 and prognosis in children with malignant gliomas. N Engl J Med 2002;346:420-427.

82. Campbell JW, Pollack IF, Martinez AJ, Shultz B. High-grade astrocytomas in children: radiologically complete resection is associated with an excellent long-term prognosis. Neurosurgery 1996;38:258-264.

83. Finlay JL, Boyett JM, Yates AJ, et al. Randomized phase III trial in childhood high-grade astrocytoma comparing vincristine, lomustine, and prednisone with the eight-drugs-in-1-day regimen. Childrens Cancer Group. J Clin Oncol 1995;13:112-123.

84. Wisoff JH, Boyett JM, Berger MS, et al. Current neurosurgical management and the impact of the extent of resection in the treatment of malignant gliomas of childhood: a report of the Children's Cancer Group trial no. CCG-945. J Neurosurg 1998; 89:52-59.

85. Wolff JE, Gnekow AK, Kortmann RD, et al. Preradiation chemotherapy for pediatric patients with high-grade glioma. Cancer 2002;94:264-271.

86. Fulton DS, Urtasun RC, Scott-Brown I, et al. Increasing radiation dose intensity using hyperfractionation in patients with malignant glioma. Final report of a prospective phase I-II dose response study. J Neurooncol 1992;14:63-72.

87. Sposto R, Ertel IJ, Jenkin RD, et al. The effectiveness of chemotherapy for treatment of high grade astrocytoma in children: results of a randomized trial. A report from the Childrens Cancer Study Group. J Neurooncol 1989;7:165-177.

88. Finlay JL, Zacharoulis S. The treatment of high grade gliomas and diffuse intrinsic pontine tumors of childhood and adolescence: a historical — and futuristic — perspective. J Neurooncol 2005; 75:253-266.

89. Pollack IF, Boyett JM, Yates AJ, et al. The influence of central review on outcome associations in childhood malignant gliomas: results from the CCG-945 experience. Neuro Oncol 2003;5: 197-207.

90. MacDonald TJ, Arenson EB, Ater J, et al. Phase II study of high-dose chemotherapy before radiation in children with newly diagnosed high-grade astrocytoma: final analysis of Children's Cancer Group Study 9933. Cancer 2005;104:2862-2871.

91. Chastagner P, Kalifa C, Doz F, et al. Outcome of children treated with preradiation chemotherapy for a high-grade glioma: results of a French Society of Pediatric Oncology (SFOP) Pilot Study. Pediatr Blood Cancer 2007;49:803-807.

92. Estlin EJ, Lashford L, Ablett S, et al. Phase I study of temozolomide in paediatric patients with advanced cancer. United Kingdom Children's Cancer Study Group. Br J Cancer 1998;78:652661.

93. Lashford LS, Thiesse P, Jouvet A, et al. Temozolomide in malignant gliomas of childhood: a United Kingdom Children's Cancer Study Group and French Society for Pediatric Oncology Intergroup Study. J Clin Oncol 2002;20:4684-4691.

94. Nicholson HS, Kretschmar CS, Krailo M, et al. Phase 2 study of temozolomide in children and adolescents with recurrent central nervous system tumors: a report from the Children's Oncology Group. Cancer 2007;110:1542-1550.

95. Vredenburgh JJ, Desjardins A, Herndon JE, 2nd, et al. Phase II trial of bevacizumab and irinotecan in recurrent malignant glioma. Clin Cancer Res 2007;13:1253-1259.

96. Broniscer A, Baker SJ, Stewart CF, et al. Phase I and pharmacokinetic studies of erlotinib administered concurrently with radiotherapy for children, adolescents, and young adults with highgrade glioma. Clin Cancer Res 2009;15:701-707.

97. Pollack IF, Jakacki RI, Blaney SM, et al. Phase I trial of imatinib in children with newly diagnosed brainstem and recurrent malignant gliomas: a Pediatric Brain Tumor Consortium report. Neuro Oncol 2007;9:145-160.

98. Laws ER, Jr., Taylor WF, Clifton MB, Okazaki H. Neurosurgical management of low-grade astrocytoma of the cerebral hemispheres. J Neurosurg 1984;61:665-673.

99. Pollack IF, Claassen D, al-Shboul Q, Janosky JE, Deutsch M. Low-grade gliomas of the cerebral hemispheres in children: an analysis of 71 cases. J Neurosurg 1995;82:536-547.

100. Schneider JH, Jr., Raffel C, McComb JG. Benign cerebellar astrocytomas of childhood. Neurosurgery 1992;30:58-62.

101. Benesch M, Eder HG, Sovinz P, et al. Residual or recurrent cerebellar low-grade glioma in children after tumor resection: is re-treatment needed? A single center experience from 1983 to 2003. Pediatr Neurosurg 2006;42:159-164.

102. Garcia DM, Marks JE, Latifi HR, Kliefoth AB. Childhood cerebellar astrocytomas: is there a role for postoperative irradiation? Int J Radiat Oncol Biol Phys 1990;18:815-818.

103. Watson GA, Kadota RP, Wisoff JH. Multidisciplinary management of pediatric low-grade gliomas. Semin Radiat Oncol 2001; 11:152-162.

104. Listernick R, Darling C, Greenwald M, Strauss L, Charrow J. Optic pathway tumors in children: the effect of neurofibromatosis type 1 on clinical manifestations and natural history. J Pediatr $1995 ; 127: 718-722$.

105. Fouladi M, Hunt DL, Pollack IF, et al. Outcome of children with centrally reviewed low-grade gliomas treated with chemotherapy with or without radiotherapy on Children's Cancer Group highgrade glioma study CCG-945. Cancer 2003;98:1243-1252.

106. Mishra KK, Puri DR, Missett BT, et al. The role of up-front radiation therapy for incompletely resected pediatric WHO grade II low-grade gliomas. Neuro Oncol 2006;8:166-174.

107. Marcus KJ, Goumnerova L, Billett AL, et al. Stereotactic radiotherapy for localized low-grade gliomas in children: final results of a prospective trial. Int J Radiat Oncol Biol Phys 2005;61:374379.

108. Packer RJ, Lange B, Ater J, et al. Carboplatin and vincristine for recurrent and newly diagnosed low-grade gliomas of childhood. J Clin Oncol 1993;11:850-856.

109. Packer RJ, Ater J, Allen J, et al. Carboplatin and vincristine chemotherapy for children with newly diagnosed progressive low-grade gliomas. J Neurosurg 1997;86:747-754.

110. Perilongo G. Considerations on the role of chemotherapy and modern radiotherapy in the treatment of childhood low grade glioma. J Neurooncol 2005;75:301-307.

111. Massimino M, Spreafico F, Cefalo G, et al. High response rate to cisplatin/etoposide regimen in childhood low-grade glioma. J Clin Oncol 2002;20:4209-4216.

112. Gururangan S, Cavazos CM, Ashley D, et al. Phase II study of carboplatin in children with progressive low-grade gliomas. J Clin Oncol 2002;20:2951-2958.

113. Kuo DJ, Weiner HL, Wisoff $\mathrm{J}$, et al. Temozolomide is active in childhood, progressive, unresectable, low-grade gliomas. J Pediatr Hematol Oncol 2003;25:372-378.

114. Cheng Y, Pang JC, Ng HK, et al. Pilocytic astrocytomas do not show most of the genetic changes commonly seen in diffuse astrocytomas. Histopathology 2000;37:437-444.

115. Bigner SH, McLendon RE, Fuchs H, McKeever PE, Friedman HS. Chromosomal characteristics of childhood brain tumors. Cancer Genet Cytogenet 1997;97:125-134.

116. Orr LC, Fleitz J, McGavran L, et al. Cytogenetics in pediatric low-grade astrocytomas. Med Pediatr Oncol 2002;38:173-177. 
117. Sanoudou D, Tingby O, Ferguson-Smith MA, Collins VP, Coleman N. Analysis of pilocytic astrocytoma by comparative genomic hybridization. Br J Cancer 2000;82:1218-1222.

118. Jones DT, Ichimura K, Liu L, et al. Genomic analysis of pilocytic astrocytomas at $0.97 \mathrm{Mb}$ resolution shows an increasing tendency toward chromosomal copy number change with age. J Neuropathol Exp Neurol 2006;65:1049-1058.

119. Zattara-Cannoni H, Gambarelli D, Lena G, et al. Are juvenile pilocytic astrocytomas benign tumors? A cytogenetic study in 24 cases. Cancer Genet Cytogenet 1998;104:157-160.

120. Pfister S, Janzarik WG, Remke M, et al. BRAF gene duplication constitutes a mechanism of MAPK pathway activation in lowgrade astrocytomas. J Clin Invest 2008;118:1739-1749.

121. Bar EE, Lin A, Tihan T, Burger PC, Eberhart CG. Frequent gains at chromosome 7q34 involving BRAF in pilocytic astrocytoma. J Neuropathol Exp Neurol 2008;67:878-887.

122. Jones DT, Kocialkowski S, Liu L, et al. Tandem duplication producing a novel oncogenic BRAF fusion gene defines the majority of pilocytic astrocytomas. Cancer Res 2008;68:8673-8677.

123. Chico-Ponce de Leon F, Perezpena-Diazconti M, Castro-Sierra E, et al. Stereotactically-guided biopsies of brainstem tumors. Childs Nerv Syst 2003;19:305-310.

124. Roujeau T, Machado G, Garnett MR, et al. Stereotactic biopsy of diffuse pontine lesions in children. J Neurosurg 2007;107:1-4.

125. Sanford RA, Freeman CR, Burger P, Cohen ME. Prognostic criteria for experimental protocols in pediatric brainstem gliomas. Surg Neurol 1988;30:276-280.

126. Zagzag D, Miller DC, Knopp E, et al. Primitive neuroectodermal tumors of the brainstem: investigation of seven cases. Pediatrics 2000;106:1045-1053.

127. Freeman CR, Farmer JP. Pediatric brain stem gliomas: a review. Int J Radiat Oncol Biol Phys 1998;40:265-271.

128. Haas-Kogan DA, Banerjee A, Kocak M, et al. Phase I trial of tipifarnib in children with newly diagnosed intrinsic diffuse brainstem glioma. Neuro Oncol 2008;10:341-347.

129. Albright AL, Packer RJ, Zimmerman R, et al. Magnetic resonance scans should replace biopsies for the diagnosis of diffuse brain stem gliomas: a report from the Children's Cancer Group. Neurosurgery 1993;33:1026-1029; discussion 1029-1030.

130. Epstein F, Constantini S. Practical decisions in the treatment of pediatric brain stem tumors. Pediatr Neurosurg 1996;24: 24-34.

131. Packer RJ, Boyett JM, Zimmerman RA, et al. Outcome of children with brain stem gliomas after treatment with $7800 \mathrm{cGy}$ of hyperfractionated radiotherapy. A Childrens Cancer Group Phase I/II Trial. Cancer 1994;74:1827-1834.

132. Freeman CR, Krischer JP, Sanford RA, et al. Final results of a study of escalating doses of hyperfractionated radiotherapy in brain stem tumors in children: a Pediatric Oncology Group study. Int J Radiat Oncol Biol Phys 1993;27:197-206.

133. Mandell LR, Kadota R, Freeman C, et al. There is no role for hyperfractionated radiotherapy in the management of children with newly diagnosed diffuse intrinsic brainstem tumors: results of a Pediatric Oncology Group phase III trial comparing conventional vs. hyperfractionated radiotherapy. Int J Radiat Oncol Biol Phys 1999;43:959-964.

134. Jennings MT, Sposto R, Boyett JM, et al. Preradiation chemotherapy in primary high-risk brainstem tumors: phase II study CCG-9941 of the Children's Cancer Group. J Clin Oncol 2002; 20:3431-3437.

135. Freeman CR, Kepner J, Kun LE, et al. A detrimental effect of a combined chemotherapy-radiotherapy approach in children with diffuse intrinsic brain stem gliomas? Int J Radiat Oncol Biol Phys 2000;47:561-564.

136. Bouffet E, Raquin M, Doz F, et al. Radiotherapy followed by high dose busulfan and thiotepa: a prospective assessment of high dose chemotherapy in children with diffuse pontine gliomas. Cancer 2000;88:685-692.

137. Dunkel IJ, O’Malley B, Finlay JL. Is there a role for high-dose chemotherapy with stem cell rescue for brain stem tumors of childhood? Pediatr Neurosurg 1996;24:263-266.

138. Finlay JL. The role of high-dose chemotherapy and stem cell rescue in the treatment of malignant brain tumors. Bone Marrow Transplant 1996;18(suppl 3):S1-5.

139. Frappaz D, Schell M, Thiesse P, et al. Preradiation chemotherapy may improve survival in pediatric diffuse intrinsic brainstem gliomas: final results of BSG 98 prospective trial. Neuro Oncol 2008;10:599-607.

140. Sirachainan N, Pakakasama S, Visudithbhan A, et al. Concurrent radiotherapy with temozolomide followed by adjuvant temozolomide and cis-retinoic acid in children with diffuse intrinsic pontine glioma. Neuro Oncol 2008;10:577-582.

141. Hargrave D, Bartels U, Bouffet E. Diffuse brainstem glioma in children: critical review of clinical trials. Lancet Oncol 2006;7: 241-248.

142. Hargrave D, Chuang N, Bouffet E. Conventional MRI cannot predict survival in childhood diffuse intrinsic pontine glioma. J Neurooncol 2008;86:313-319.

143. Daw NC, Furman WL, Stewart CF, et al. Phase I and pharmacokinetic study of gefitinib in children with refractory solid tumors: a Children's Oncology Group Study. J Clin Oncol 2005; 23:6172-6180.

144. Freeman BB, 3rd, Daw NC, Geyer JR, Furman WL, Stewart CF. Evaluation of gefitinib for treatment of refractory solid tumors and central nervous system malignancies in pediatric patients. Cancer Invest 2006;24:310-317.

145. Packer RJ, Krailo M, Mehta M, et al. A Phase I study of concurrent RMP-7 and carboplatin with radiation therapy for children with newly diagnosed brainstem gliomas. Cancer 2005;104: $1968-1974$.

146. Ross GW, Rubinstein LJ. Lack of histopathological correlation of malignant ependymomas with postoperative survival. J Neurosurg 1989;70:31-36.

147. Bouffet E, Perilongo G, Canete A, Massimino M. Intracranial ependymomas in children: a critical review of prognostic factors and a plea for cooperation. Med Pediatr Oncol 1998;30:319-329; discussion 329-331.

148. Robertson PL, Zeltzer PM, Boyett JM, et al. Survival and prognostic factors following radiation therapy and chemotherapy for ependymomas in children: a report of the Children's Cancer Group. J Neurosurg 1998;88:695-703.

149. McGuire CS, Sainani KL, Fisher PG. Both location and age predict survival in ependymoma: a SEER study. Pediatr Blood Cancer 2009;52:65-69.

150. Timmermann B, Kortmann RD, Kuhl J, et al. Combined postoperative irradiation and chemotherapy for anaplastic ependymomas in childhood: results of the German prospective trials HIT 88/89 and HIT 91. Int J Radiat Oncol Biol Phys 2000;46:287295.

151. Goldwein JW, Corn BW, Finlay JL, et al. Is craniospinal irradiation required to cure children with malignant (anaplastic) intracranial ependymomas? Cancer 1991;67:2766-2771.

152. Merchant TE, Mulhern RK, Krasin MJ, et al. Preliminary results from a phase II trial of conformal radiation therapy and evaluation of radiation-related CNS effects for pediatric patients with localized ependymoma. J Clin Oncol 2004;22:3156-3162.

153. Rousseau P, Habrand JL, Sarrazin D, et al. Treatment of intracranial ependymomas of children: review of a 15-year experience. Int J Radiat Oncol Biol Phys 1994;28:381-386.

154. MacDonald SM, Safai S, Trofimov A, et al. Proton radiotherapy for childhood ependymoma: initial clinical outcomes and dose comparisons. Int J Radiat Oncol Biol Phys 2008;71:979-986.

155. McLaughlin MP, Marcus RB, Jr., Buatti JM, et al. Ependymoma: results, prognostic factors and treatment recommendations. Int J Radiat Oncol Biol Phys 1998;40:845-850.

156. Vanuytsel L, Brada M. The role of prophylactic spinal irradiation in localized intracranial ependymoma. Int J Radiat Oncol Biol Phys 1991;21:825-830.

157. Aggarwal R, Yeung D, Kumar P, Muhlbauer M, Kun LE. Efficacy and feasibility of stereotactic radiosurgery in the primary management of unfavorable pediatric ependymoma. Radiother Oncol 1997;43:269-273.

158. Kalapurakal JA, Goldman S, Stellpflug W, et al. Phase I study of intraoperative radiotherapy with photon radiosurgery system in children with recurrent brain tumors: preliminary report of first 
dose level (10 Gy). Int J Radiat Oncol Biol Phys 2006;65: $800-808$.

159. Grundy RG, Wilne SA, Weston CL, et al. Primary postoperative chemotherapy without radiotherapy for intracranial ependymoma in children: the UKCCSG/SIOP prospective study. Lancet Oncol 2007;8:696-705.

160. Duffner PK, Krischer JP, Sanford RA, et al. Prognostic factors in infants and very young children with intracranial ependymomas. Pediatr Neurosurg 1998;28:215-222.

161. Grill J, Le Deley MC, Gambarelli D, et al. Postoperative chemotherapy without irradiation for ependymoma in children under 5 years of age: a multicenter trial of the French Society of Pediatric Oncology. J Clin Oncol 2001;19:1288-1296.

162. Hargrave DR, Zacharoulis S. Pediatric CNS tumors: current treatment and future directions. Expert Rev Neurother 2007;7:10291042.

163. Evans AE, Anderson JR, Lefkowitz-Boudreaux IB, Finlay JL. Adjuvant chemotherapy of childhood posterior fossa ependymoma: cranio-spinal irradiation with or without adjuvant CCNU, vincristine, and prednisone: a Childrens Cancer Group study. Med Pediatr Oncol 1996;27:8-14.

164. Zacharoulis S, Levy A, Chi SN, et al. Outcome for young children newly diagnosed with ependymoma, treated with intensive induction chemotherapy followed by myeloablative chemotherapy and autologous stem cell rescue. Pediatr Blood Cancer 2007;49: $34-40$.
165. Ebert C, von Haken M, Meyer-Puttlitz B, et al. Molecular genetic analysis of ependymal tumors. NF2 mutations and chromosome 22q loss occur preferentially in intramedullary spinal ependymomas. Am J Pathol 1999;155:627-632.

166. Gutmann DH, Giordano MJ, Fishback AS, Guha A. Loss of merlin expression in sporadic meningiomas, ependymomas and schwannomas. Neurology 1997;49:267-270.

167. Rubio MP, Correa KM, Ramesh V, et al. Analysis of the neurofibromatosis 2 gene in human ependymomas and astrocytomas. Cancer Res 1994;54:45-47.

168. Rajaram V, Gutmann DH, Prasad SK, Mansur DB, Perry A. Alterations of protein 4.1 family members in ependymomas: a study of 84 cases. Mod Pathol 2005;18:991-997.

169. Mendrzyk F, Korshunov A, Benner A, et al. Identification of gains on 1q and epidermal growth factor receptor overexpression as independent prognostic markers in intracranial ependymoma. Clin Cancer Res 2006;12:2070-2079.

170. Modena P, Lualdi E, Facchinetti F, et al. Identification of tumorspecific molecular signatures in intracranial ependymoma and association with clinical characteristics. J Clin Oncol 2006;24: 5223-5233.

171. Poppleton H, Gilbertson RJ. Stem cells of ependymoma. Br J Cancer 2007;96:6-10.

172. Taylor MD, Poppleton H, Fuller C, et al. Radial glia cells are candidate stem cells of ependymoma. Cancer Cell 2005;8:323335 . 